\title{
Evaluation/improvement of in-cab air quality at an interstate travel center with truck stop electrification
}

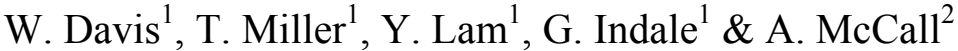 \\ ${ }^{I}$ Department of Civil and Environmental Engineering, \\ University of Tennessee, Knoxville, TN, USA \\ ${ }^{2}$ IdleAire Technologies Corporation, Knoxville, TN, USA
}

\begin{abstract}
This paper presents the results of a study conducted in 2004-2005 related to the measurement of ambient air quality and Heavy Duty Diesel Vehicle (HDDV) cabin air quality in the vicinity of a major interstate travel center in which truck stop electrification (TSE) had been installed to reduce idling of heavy duty diesel truck emissions in a section of the travel center. The paper provides 1) a summary of the ambient air quality $\left(\mathrm{PM}_{2.5}, \mathrm{NO}_{\mathrm{x}}\right.$ and $\left.\mathrm{CO}\right)$ in the vicinity of the travel center which contains approximately 225 HDDV parking spaces, including both TSE and non-TSE parking spaces 2) the results of a study that was conducted to compare the HDDV cabin air quality $\left(\mathrm{PM}_{2.5}\right)$ to that of the ambient air under various truck idling operating conditions, including idling, idling with the truck's heating ventilation air conditioning (HVAC) system on external air circulation, idling with the truck HVAC on Max AC with internal air circulation, and no idling with the truck utilizing TSE, and 3) improvements in cabin air quality achieved by installing a more efficient filter medium in the HVAC system of the TSE system.

Keywords: air quality, $P M_{2.5}$, diesel truck emissions, truck stop electrification, idling emissions, air filtration, cabin air quality, particle size.
\end{abstract}

\section{Introduction}

The Department of Transportation (DOT) in the U.S. requires truck drivers to rest for extended periods when transporting goods on public highways. During this time and while waiting for loading and unloading of their trucks, truck 
drivers idle their engines to provide heating or air conditioning for the cab and sleeping compartment, keeping the engines warm during cold climate, and providing electrical power for their onboard appliances. At large travel centers where the drivers rest, 200 or more trucks may be idling at any one time. At these truck stops idling emissions can significantly contribute to the concentrations of air pollutants in the ambient air in the vicinity of the truck stop, as well as within the diesel truck cabs in which the drivers are resting. Technologies, including Truck Stop Electrification (TSE), are being developed and installed at travel centers to minimize the idling time and subsequent emission of air pollutants.

The paper provides 1) a summary of the ambient air quality $\left(\mathrm{PM}_{2.5}, \mathrm{NO}_{\mathrm{x}}\right.$ and $\mathrm{CO})$ in the vicinity of a travel center which contains approximately $225 \mathrm{HDDV}$ parking spaces, including both TSE and non-TSE parking spaces 2) the results of a study that was conducted to compare the HDDV cabin air quality to that of the ambient air under various truck idling operating conditions, including idling, idling with the truck's heating ventilation air conditioning (HVAC) system on external air circulation, idling with the truck HVAC on Max AC with internal air circulation, and no idling with the truck utilizing TSE, and 3) improvements in cabin air quality achieved by installing more efficient filter media in the Heating Ventilation Air Conditioning system of the TSE system.

\section{Air Quality in a travel center}

A study was conducted to monitor the ambient air quality at a truck travel center located at the intersection of Interstates I40/I75 and Watt Road near Knoxville TN between mid December 2003 and August 2004. The study was conducted as part of a project funded by the Federal Highway Administration in which funds were provided for the installation of Truck Stop Electrification in a section of the travel center's truck parking lot [1]. Ambient monitors were installed at two locations inside the travel center, one at the center and one near the edge of the center to continuously measure ambient concentrations of $\mathrm{NO}_{\mathrm{x}}, \mathrm{PM}_{2.5}$, and $\mathrm{CO}$. Continuous measurements of $\mathrm{PM}_{2.5}$ and $\mathrm{NO}_{\mathrm{x}}$ were made at the two monitoring trailers while $\mathrm{CO}$ was measured only at one of the trailers. Two Met One EBAM beta gage instruments for $\mathrm{PM}_{2.5}$, two Teledyne M200E Chemiluminescence $\mathrm{NO}_{x}$ analyzers and one Non-Dispersive Infrared (NDIR) CO analyzer were used to monitor the pollutants. Air samples were drawn from sampling probes on the trailer roofs at a height of 4 meters above the ground.

In general, concentrations of $\mathrm{NO}_{\mathrm{x}}, \mathrm{PM}_{2.5}$ and $\mathrm{CO}$ were found to be the highest during nighttime and early morning hours compared to daytime. This corresponds to the period associated with increased atmospheric stability as well as the period of highest occupation by diesel trucks. The number of trucks idling at the truck travel center typically varied from approximately 60 at noon to approximately 130 during the period of $10 \mathrm{pm}$ to 6 am and represented between $60-70 \%$ of the total number of trucks parked in the center. The averages of the 24-hr ambient concentrations of $\mathrm{PM}_{2.5}$ were $35 \mu \mathrm{g} / \mathrm{m}^{3}$ and $29 \mu \mathrm{g} / \mathrm{m}^{3}$ for trailers \#1 and \#2 for the nine month period over which the data were monitored. 
Figure 1 illustrates the $24 \mathrm{hr}$ average concentration of $\mathrm{PM}_{2.5}$ for Trailer \#1. The data showed that the 24-hr average $\mathrm{PM}_{2.5}$ concentrations were greater than the annual average NAAQS of $15 \mu \mathrm{g} / \mathrm{m}^{3}$ [2] at trailer $\# 1$ for each day that was monitored. At trailer \#2 (not shown) the 24-hr average values were greater than the standard on $95 \%$ of the monitored days. The highest $24 \mathrm{hr}$ average value at trailer \#1 was $116 \mu \mathrm{g} / \mathrm{m}^{3}$ and exceeded the 24-hr NAAQS of $65 \mu \mathrm{g} / \mathrm{m}^{3}$ [2] four times, whereas values at trailer \#2 exceeded 6 times, with the same highest value. The values obtained in the travel center are substantially greater than the ambient concentrations observed by other monitors in the Knoxville and surrounding area which did not exceed the 24-hr standard. A comparable station located approximately $40 \mathrm{~km}$ from the travel center had an average 24-hr mean $\mathrm{PM}_{2.5}$ concentration of $13 \mu \mathrm{g} / \mathrm{m}^{3}$ during this same period.

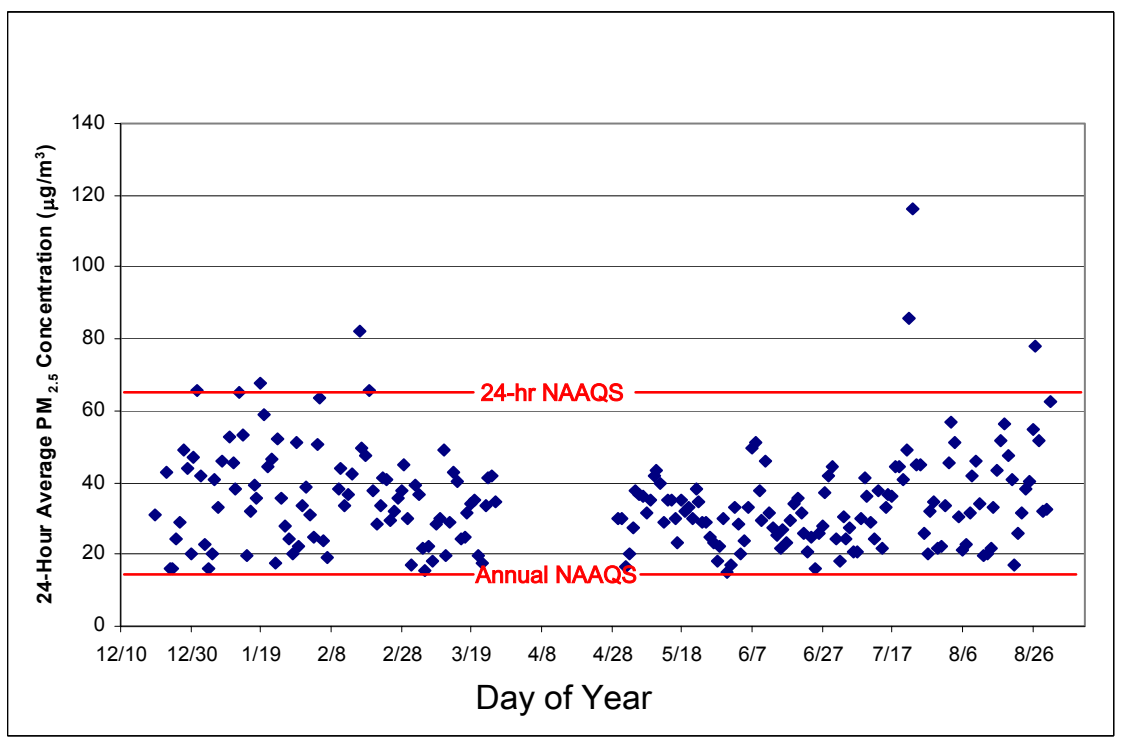

Figure 1: $\quad \mathrm{PM}_{2.5}$ concentration at trailer \# 1 .

Figure 2 shows concentrations of $\mathrm{NOx}$ as $\mathrm{NO}$ and $\mathrm{NO}_{2}$ during the study period. Concentrations of $\mathrm{NO}_{2}$ were at or near the annual NAAQS for $\mathrm{NO}_{2}$ of $53 \mathrm{ppb}$ [2] for the entire period of the study. The average NOx concentrations at trailer \#1 and \#2 were 276 and $213 \mathrm{ppb}$ for the nine month period. The ratio of $\mathrm{NO}$ to $\mathrm{NO}_{2}$ was approximately 4/1, which is typical of newly emitted NOx from combustion sources. One-hr average concentrations of $\mathrm{CO}$ never exceeded $1.9 \mathrm{ppm}$ compared to the NAAQS of $35 \mathrm{ppm}$ [2]. This was expected since diesel engines which operate under high excess air conditions generally emit low concentrations of carbon monoxide. 


\section{Effect of TSE on ambient air quality in diesel cabs}

The idling of a large number of diesel trucks was shown above to create high concentrations of certain pollutants in the vicinity of the parked and idling trucks. To that end, the drivers of the idling vehicles and other personnel in the area are exposed to higher concentrations than would be necessary if Truck Stop Electrification (TSE) or other idling reduction technologies were applied. The second part of this paper concentrates on the evaluation of the air quality inside of diesel cabs that were parked in the travel center area and the impact of TSE on the air quality inside the cabs. This part of the study focused only on particulate matter, although some inferences can be made regarding the effect of TSE on other pollutants. The study focused on a comparison of the HDDV cabin air quality (PM) to that of the ambient air under various truck idling operating conditions. These included the operation of trucks under the following types of conditions: 1) the truck idling at $800 \mathrm{rpm}$ with the truck's air conditioning system operating on high speed (4 AC) with outside air circulation, 2) the truck idling at $800 \mathrm{rpm}$ with the truck's air conditioning system operating on MAX $\mathrm{A} / \mathrm{C}$ (internal air circulation), and 3 ) the truck off and connected to the IdleAire TSE system which provided air conditioning via the external air handling system operating under the maximum air conditioning setting. The concentrations of particulate matter were evaluated as a direct measure of the air quality.

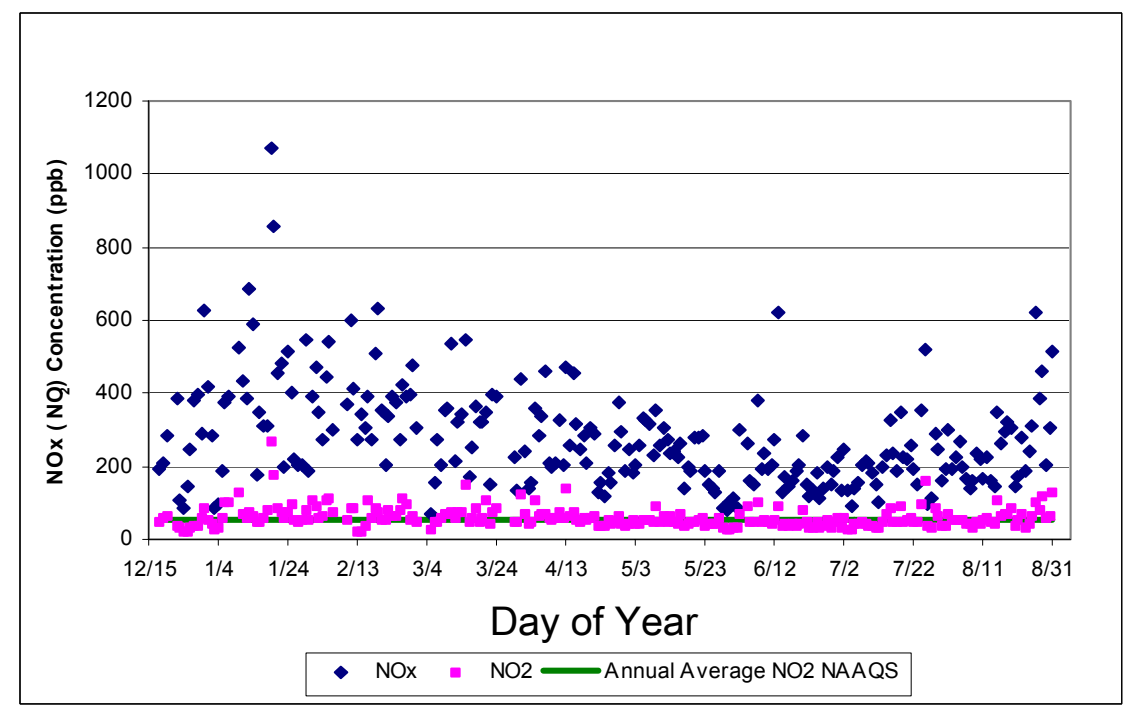

Figure 2: $\quad \mathrm{NO}_{\mathrm{x}}$ concentration at trailer \# 1 .

\subsection{Methodology}

The air quality was measured by monitoring the particle concentrations inside and outside of the vehicle with a Climet Model CI-7300 Laser Particle Counter 
which simultaneously monitored the number concentration of the particles in six size ranges: $0.3-0.5,0.5-0.7,0.7-1.0,1.0-5.0$, and 5.0-10.0 $\mu \mathrm{m}$. Samples were collected for thirty seconds and recorded every minute throughout each test. The number concentration for each size range was converted to an equivalent mass concentration by multiplying the number of particles by the volume of the mean size in each particle interval to obtain the equivalent volume concentration. This concentration was converted to an equivalent mass concentration in micrograms per cubic meter $\left(\mu \mathrm{g} / \mathrm{m}^{3}\right)$ by assuming a particle density of $2.5 \mathrm{~g} / \mathrm{cm}^{3}(2500$ $\mathrm{kg} / \mathrm{m}^{3}$ ). The mass concentration in the range of $0.3-10.0 \mu \mathrm{m}$ was determined by summing the concentrations in each channel.

The methodology included the measurement of air quality concentrations in a number of different operating conditions, defined as follows:

T-OFF OUT - testing of the outside air concentration just outside the driver's side window with the truck off. This condition provides a direct measure of the air quality in the vicinity of the truck being tested.

$T$-ON OUT - testing of the outside air concentration just outside the driver's side window with the truck on. This condition provides a direct measure of the air quality in the vicinity of the truck during periods when the truck's engine was running and the truck's $\mathrm{A} / \mathrm{C}$ system was being operated.

$T-O N$ 4- $A C$ - testing of the air concentrations inside the diesel truck cabin with the engine idling at $800 \mathrm{rpm}$ and the $\mathrm{A} / \mathrm{C}$ operating on the highest setting (setting 4). In this mode, the $\mathrm{A} / \mathrm{C}$ system brings outside air into the truck while also circulating the air through the truck's air circulation system. The inside concentrations were measured at a position in the center of the sleeper cab area approximately 30 inches off of the floor.

$T$-ON MAX AC - testing of the air concentrations inside the diesel cabin with the engine idling at $800 \mathrm{rpm}$ and the $\mathrm{A} / \mathrm{C}$ setting on the $M A X A C$ setting. In this mode, the truck's A/C system operates in a closed loop recirculation mode.

$T$-OFF $I A-O N$ - testing in which the truck engine was turned off and the diesel cabin was cooled by the TSE A/C system (see Figure 2) which was placed in the passenger side window. The TSE system was operated on the cool setting with the thermostat set at $65^{\circ} \mathrm{F}$ which represents a maximum airflow mode. The flowrate of the $\mathrm{A} / \mathrm{C}$ system is approximately $350 \mathrm{cfm}$ and contains an HVAC filter that is utilized to remove particles from the air.

The above types of tests were conducted on sixteen different trucks during the period of July through August, 2004 on a standard pleated meltblown filter that had an activated carbon impregnated layer, referred to here as the C-filter. At the onset of the study, this filter was being utilized in the TSE systems at the Watt Road Facility. While the initial objective of the study was to characterize the TSE system with this standard filter, a second objective was to identify alternative filters that might represent improved filter efficiency and improved air quality within the diesel cabins utilizing the TSE system. Ten different commercially available filters were evaluated to determine their filtration characteristics (efficiency and pressure drop) and to identify possible candidate filters for improvement of the TSE system. A final candidate filter, referred to as 
Synfil 12 was chosen to be used in future TSE installations and the results of preliminary testing are summarized in the results.

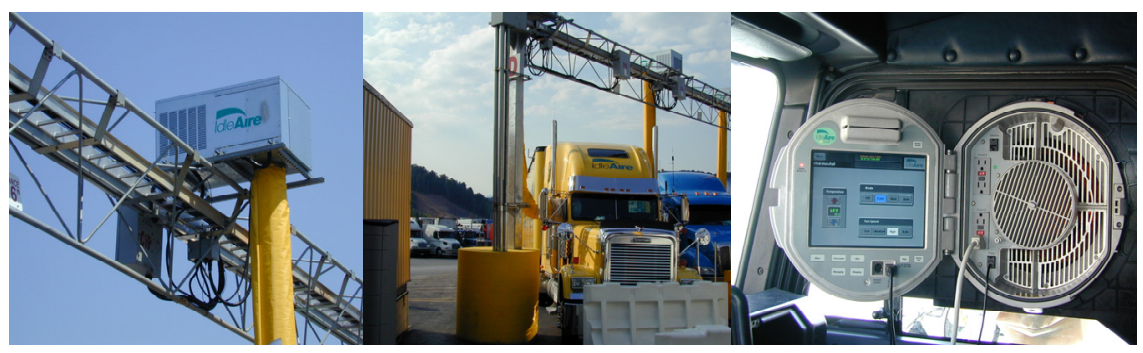

Figure 3: $\quad$ Photos of TSE A/C system and window unit.

\subsection{Detailed results of testing on two trucks}

In an effort to illustrate the actual effect of the above types of test on the air quality in the diesel truck cabins, and to illustrate two extreme cases, a detailed summary of the tests conducted on two of the sixteen trucks tested is included prior to summarizing the results of all of the tests. Figure 4 shows the results of the tests on Truck 1. The graph shows a plot of the mass concentration of particles $(0.3-10.0 \mu \mathrm{m})$ versus time. A brief discussion is presented here describing the observations that were made.

For Truck 1, the initial concentration in the ambient outside air with the truck off (T-OFF OUT) was about $20.4 \mu \mathrm{g} / \mathrm{m}^{3}$. The truck was then turned on. The indoor air quality with the truck on with $4-A C$ (T-ON 4AC) was about 25 $\mu \mathrm{g} / \mathrm{m}^{3}$ and began to increase to $70 \mu \mathrm{g} / \mathrm{m}^{3}$. The outdoor concentration (T-ON OUT) was checked and was found to be highly variable, but increasing to as high as $150 \mu \mathrm{g} / \mathrm{m}^{3}$. This highly variable outside concentration is typical of all tests and is a result of the variable windspeed and direction that affect the truck's exhaust as well as the activity of other trucks in the vicinity of the test truck. The indoor air concentration in the $T-O N$ 4-AC mode was then rechecked and found to be $122 \mu \mathrm{g} / \mathrm{m}^{3}$. The AC was then changed to $M A X A C$. Concentrations immediately decreased to an average of $54 \mu \mathrm{g} / \mathrm{m}^{3}$, indicating that some improvement was present inside the truck when the truck was operated with internal recirculation. (There is no cabin air filter in the truck). An outside air test revealed continued high concentrations $\left(>140 \mu \mathrm{g} / \mathrm{m}^{3}\right)$. The truck was then turned off and the TSE system was turned on. The concentrations inside the truck immediately decreased from the $54 \mu \mathrm{g} / \mathrm{m}^{3}$ to $4.2 \mu \mathrm{g} / \mathrm{m}^{3}$ within 8 minutes. The air exchange rate of the truck, based on the $350 \mathrm{cfm}$ TSE A/C was 0.75 per minute, so the rapid decrease within eight minutes was expected since the TSE system has a filter that removes particles. It is significant to note that the concentration inside the cabin decreased by over $90 \%$ when the truck was placed in the T-OFF IA ON mode compared to the system operating in the T-ON MAX AC mode. It is also significant to note that the outside air concentration also decreased as soon as the truck was turned off to values of 8.7 and $13.1 \mu \mathrm{g} / \mathrm{m}^{3}$ (avg of 10.9). This is 
compared to the in-cab concentrations of $4.2,5.2$ and $7.9 \mu \mathrm{g} / \mathrm{m}^{3}$ (avg of $5.7 \mu \mathrm{g} / \mathrm{m}^{3}$ ). This shows that the filter system reduces the concentration inside by approximately $47 \%$ when compared to the outside air. Compared to the air quality in the $M A X A C$ mode, however, when the truck is on, the reduction to $5.7 \mu \mathrm{g} / \mathrm{m}^{3}$ is a $91 \%$ improvement - the true improvement in indoor air quality when comparing the two modes. In essence, a large part of this truck's inside concentration is created by the operating truck itself, as evidenced by the rapid drop in concentration both outside and inside the truck when the truck was turned off.

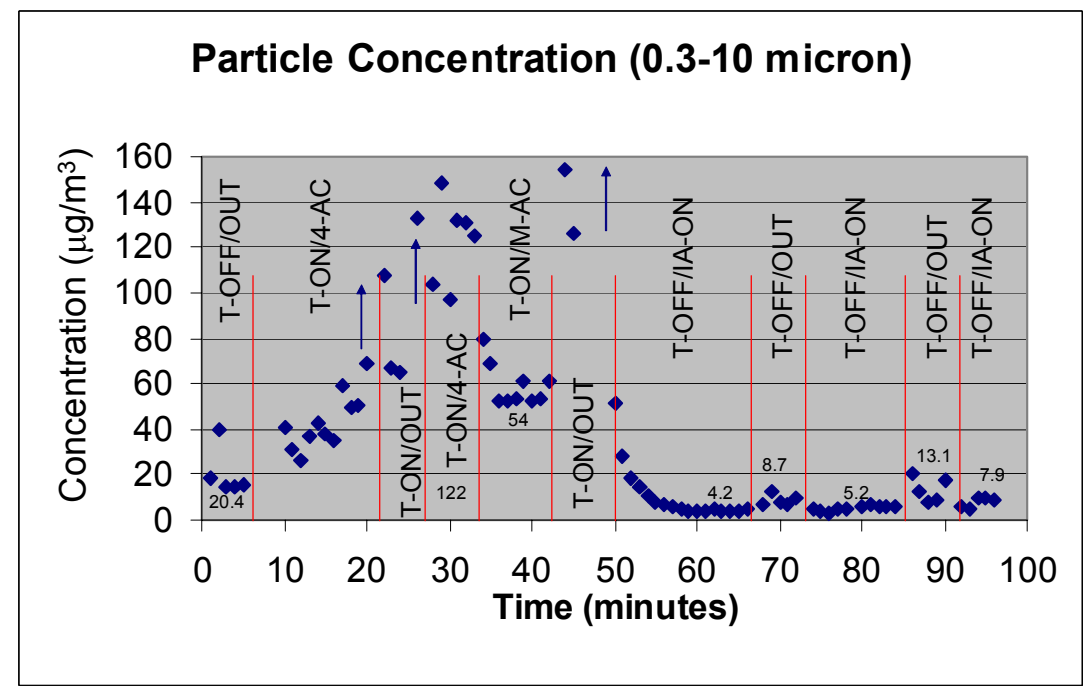

Truck 1: 1FUYDSEBXTH605302, ‘95

Figure 4: Results of testing on Truck 1.

Truck 3, shown in Figure 5, presented a very different situation than observed with the majority of trucks. As shown in the graph, the concentrations inside the truck continued to increase throughout the 4-AC and MAX AC tests to in excess of $350 \mu \mathrm{g} / \mathrm{m}^{3}$ within a period of less than 40 minutes, and the outside air concentration was highly variable when the truck was on. It is significant to note that the outside concentrations were generally less than the inside concentrations. It is highly likely that this truck had an internal leak of exhaust into the cab. The concentration inside the truck dropped rapidly from the $350 \mu \mathrm{g} / \mathrm{m}^{3}$ to approximately $12.5 \mu \mathrm{g} / \mathrm{m}^{3}$ within a period of less than 8 minutes as soon as the truck was turned off and the TSE system was turned on, representing in excess of a 96\% improvement in air quality. When the TSE system was compared to the outside air quality with the truck off, the improvement was approximately $70 \%$ as a result of the TSE system. 


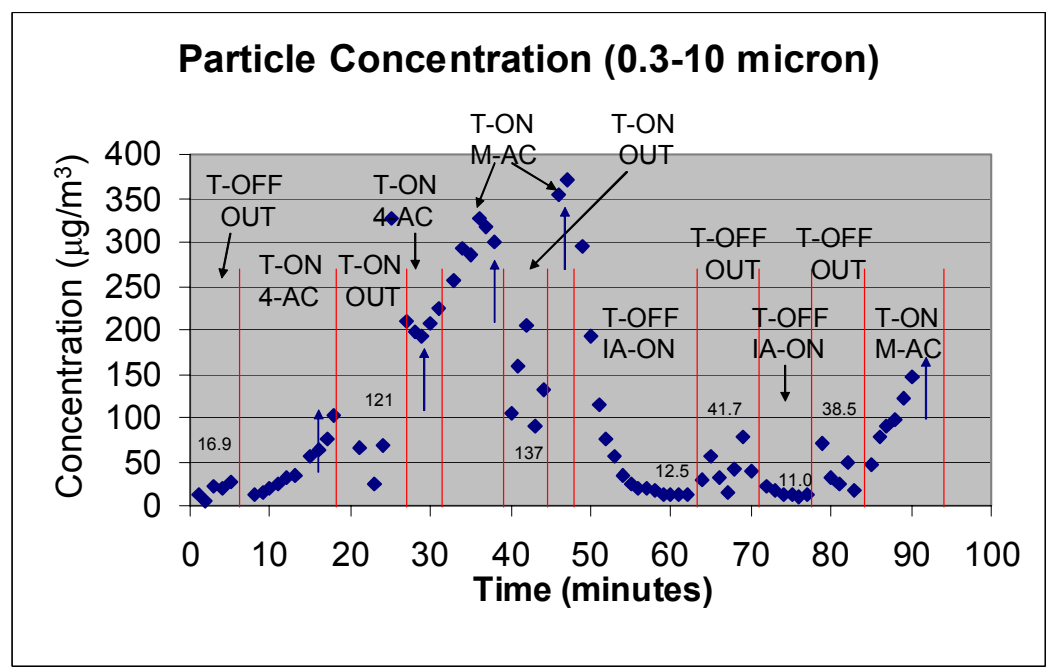

Truck 3: 1FUYDSZB3XPA22787, ‘98

Figure 5: $\quad$ Results of testing on Truck 3.

\subsection{Results of all tests on TSE with filter C}

In total, sixteen trucks were tested in which the TSE system utilized the standard meltblown filter medium with impregnated activated carbon (designated as the $\mathrm{C}$ filter), plus one repeat of Truck 1 (labelled as Truck 17). These tests are summarized in Table 1 and include tests designated as Trucks 1-17. These included a variety of ages of trucks ranging from 1995 to 2004, as well as at least one truck that was equipped with a factory installed on-board cabin air filter. Column 6 shows a comparison of the ratio of the concentration just outside the driver window with the truck on versus with the truck off. The average ratio was 3.8 with only one truck below 1.0. The value is likely very dependent on the wind direction and presence of other trucks, however, does illustrate that in most situations, the truck being tested is the largest contributor to the degradation of air quality, contributing approximately $75 \%$ of the concentration observed outside the truck window. These results show the immediate improvement in air quality that occurs as soon as a TSE system is applied (truck off). It also suggests, although not directly measured, that there would be an improvement with other pollutants, as these would no longer be emitted by the truck.

Another immediate observation is that the TSE system resulted in an overall improvement in the air quality within the cab when compared to the outside air quality in all sixteen cases that were tested. This is shown in Table 1 in column 2 by the comparison of $I A-O N$ vs. T-OFF OUT. This is a comparison which determines the percentage improvement inside the truck with the TSE system as compared to the outside air quality with the truck off using the standard filter. 
The improvement ranged from $21 \%$ to $71 \%$ with an average of $52 \%$ for the sixteen trucks that were tested.

Table 1: $\quad$ Summary of truck tests with TSE.

\begin{tabular}{|c|c|c|c|c|c|c|c|}
\hline $\begin{array}{c}\text { Test } \\
\text { Number }\end{array}$ & \begin{tabular}{|l|} 
IA-ON Vs. \\
T-OFF OUT
\end{tabular} & $\begin{array}{l}\text { IA-ON Vs. } \\
\text { MAX AC }\end{array}$ & $\begin{array}{c}\text { MAX AC Vs. } \\
\text { T-ON OUT }\end{array}$ & \begin{tabular}{|l} 
MAX AC Vs. \\
T-OFF OUT
\end{tabular} & \begin{tabular}{|l|} 
T-ON OUTI \\
T-OFF OUT
\end{tabular} & Filter & Truck Year \\
\hline & $\%$ & $\%$ & $\%$ & $\%$ & ratio & & \\
\hline Truck 1 & 47 & 91 & $>61$ & -285 & 13.8 & C & 1995 \\
\hline Truck 2 & 21 & 63 & 39 & -115 & 3.5 & C & unknown \\
\hline Truck 3 & 71 & 97 & -171 & -773 & 4.0 & $\mathrm{C}$ & 1999 \\
\hline Truck 4 & 62 & 66 & na & -13 & 3.2 & $\mathrm{C}$ & 1999 \\
\hline Truck 5 & 64 & 29 & 263 & 49 & 1.8 & $\mathrm{C}$ & 2003 \\
\hline Truck 6 & 62 & 34 & 75 & 42 & 2.3 & $\mathrm{C}$ & 1999 \\
\hline Truck 7 & 49 & 93 & 11 & -653 & 8.5 & C & 2004 \\
\hline Truck 8 & 26 & 85 & -107 & -385 & 2.3 & $\mathrm{C}$ & 2004 \\
\hline Truck 9 & 43 & 78 & -19 & -170 & 2.3 & $\mathrm{C}$ & 1995 \\
\hline Truck 10 & 58 & 73 & 40 & -54 & 2.6 & C & 2000 \\
\hline Truck 11 & 63 & 87 & 50 & -196 & 5.9 & $\mathrm{C}$ & 1995 \\
\hline Truck 12 & 64 & 3 & 84 & 23 & 2.3 & $\mathrm{C}$ & 2004 CAF? \\
\hline Truck 13 & 58 & -170 & 92 & 54 & 1.9 & $\mathrm{C}$ & $1999 \mathrm{CAF}$ \\
\hline Truck 14 & 43 & 43 & 72 & 1 & 3.6 & C & 2004 \\
\hline Truck 15 & 32 & -78 & 73 & 62 & 1.4 & C & 2004 \\
\hline Truck 16 & 67 & -365 & 91 & 93 & 0.8 & C & 2004 \\
\hline Truck 17 & 69 & 95 & -305 & -489 & 1.4 & C & 1995 \\
\hline Avg & 52 & 14 & 42 & -145 & 3.8 & & \\
\hline Truck $18 a$ & 88 & 96 & -29 & -196 & 2.3 & SF12 & 1995 \\
\hline Truck 18b & 91 & 99.4 & 2 & -1653 & 20 & SF12 & 1995 \\
\hline
\end{tabular}

A summary comparison was also made of the improvement in the truck indoor air quality achieved by the TSE system (with truck off) compared to the indoor air quality measured when the truck was operating in the MAX AC mode with the truck idling. For Year 2003 and older trucks that did not have a cabin air filter installed, the TSE system resulted in an improvement in the incab air quality ranging from 29 to $97 \%$ with an average of $69 \%$. These older trucks likely have less efficient seals around the engine cowl and doors, dirtier interiors (within the air circulation system) and no internal air filtration. However, the one 1999 truck with a cabin air filter (Truck 13) did provide substantial particle removal when operated in the $M A X A C$ mode with a $92 \%$ improvement in indoor air quality when compared to the outside air quality with the truck on. The results for the 2004 model year trucks were mixed. Four of the 2004 trucks showed improvements of between 3 and $93 \%$ for the $I A O N$ mode when compared to the MAXAC mode of operation and two of the trucks showed better performance for the $M A X A C$. This anomaly associated with the newer trucks may not continue, once these trucks are subjected to more extensive road conditions and after which they would likely behave more like the older trucks. The one older truck with cabin air filter, like the tests with the TSE System, clearly exhibited the benefit of air filtration in providing a cleaner indoor environment when the truck was idling in the travel center.

Columns 4-6 in the table do not relate directly to the TSE testing, however, they are important to note as they do indicated a general trend that occurs with 
many of the trucks that were tested. Column 4 (MAX AC vs. T-ON OUT) shows the measured improvement in air quality in the truck when compared to the air quality outside of the truck with the truck on. In most cases, the operation of the truck in the $M A X A C$ mode with the truck idling resulted in improved incab air quality-however Trucks 3, 8, 9, and 16 actually had worse incab air quality than was measured outside. As indicated earlier, these trucks are likely being contaminated by air inleakage around the engine cowl area and door seals, suggesting that these trucks are being exposed to the trucks' exhausts. Further testing would be needed to determine why these undesirable conditions are being created by certain trucks. In all situations, however, the situation is eliminated by the use of the TSE system, since the truck is no longer idling.

\subsection{Results of improved filter}

Table 1 also presents the results of the testing conducted with an improved filter, consisting of a pleated electrostatically enhanced filter (rated at MERV 12). With the change to this filter, the TSE system reduced the concentrations when compared to the outside air (with truck off) by $88-91 \%$ and reduced the concentrations when compared to the $M A X A C$ condition by $96-99.4 \%$, a significant improvement over the original lower efficiency filter. These tests were conducted on Truck 1 .

\section{References}

[1] Indale, G.T., Effects of Heavy-Duty Diesel Vehicles Idling Emissions on Ambient Air Quality at a Truck Travel Center and Air Quality Benefits Associated with Advanced Truck Stop Electrification Technology, dissertation, The University of Tennessee, Knoxville, TN, May 2005.

[2] Wark, K, Warner, C.F., \& Davis, W.T., Air Pollution: Its Origin and Control, Addison-Wesley Longmann, Inc., Menlo Park, California, p. 70, 1998. 